\title{
Preparation and properties of recycled fine powder foam concrete
}

\author{
Yongmei Feng \\ Chengdu Polytechnic, Chengdu 610041 China
}

\begin{abstract}
Abstr1act. With the rapid development of the construction industry brought by the accelerated process of urbanization, the problem of random stacking and landfill of waste concrete can be seen everywhere, which seriously affects the environmental health. The secondary utilization of waste concrete as recycled aggregate has become a research hotspot. This paper mainly studies the influence of the cementing material system of recycled fine powder foam concrete on the water absorption performance of recycled fine powder foam concrete, and explores the feasibility of using recycled fine powder to prepare foam concrete. The experiment also used recycled fine powder instead of some cement to prepare foam concrete. The effects of the amount of recycled fine powder, the amount of hydrogen peroxide and the ratio of water to binder on the compressive strength, water absorption, thermal conductivity and microstructure of the foam concrete were studied. The results showed that the water absorption rate of recycled fine powder foam concrete increased with the increase of red brick powder content, but the water absorption rate gradually increased. When the content of hydrogen peroxide is $6 \%$, the ratio of water to binder has a greater influence on the thermal conductivity of foam concrete. When the amount of hydrogen peroxide is higher, the influence of water binder ratio on thermal conductivity decreases.
\end{abstract}

key word: Regeneration powder; foam concrete; thermal conductivity; hydrog en peroxide solution.

\section{Introduction}

Blister concrete, also known as foamed concrete, belongs to a kind of porous concrete. It is made of foam made from aqueous solution of foam agent and added into cementitious materials, sand, water and admixture, and after being evenly stirred, the lightweight porous building materials formed by pouring and curing are mainly made of cement sand foam concrete, lime cement sand foam concrete and so on [1]. The prominent feature of blister concrete is that there are a large number of foam holes inside, which not only reduces the quality of foam concrete, but also keeps heat insulation. At present, the main uses of foam concrete are to use the energy saving wall materials in the north, and to make use of foamed concrete to make light wall panels, blocks and cast-in-situ roofing insulation layer [2]. However, in recent years, we have been upgrading and optimizing the properties of foam concrete, and its application scope has gradually expanded. Foam concrete is used to fill dense large cavities. Generally, holes can be used for sewer wells or subway stations that are no longer used, or for illegal construction of cellars and basements [3]. This is mainly based on the low cost and high flow self compacting characteristics of foamed concrete. By filling the foamed concrete into the reverse side of the pier to reduce the lateral pressure of the pier on the bridge structure, it can also help to reduce the settlement. Backfill foam concrete can be used to balance the foundation settlement in road repair. Foam concrete has good thermal insulation and fire resistance, and the foam concrete produced by special cement, such as high alumina cement instead of ordinary cement, has the highest resistance to 1450 degree high temperature testing, so it can be applied to high temperature furnaces. Because foam concrete has a good energy dissipation function, it can be made into the target wall in the shooting range, and it can also be applied to the underground blast resistant tunnel structure .

Construction waste recycled powder is in the use of construction waste preparation of recycled aggregate, crushing classification, screening and finishing process, will bring about the content of about $15 \%-20 \%$ of the total raw material, the average particle size is not more than $0.15 \mathrm{~mm}$ of fine particles is called recycled powder. Due to the small particle size and light weight, it is easy to be affected by the air, temperature and other environmental factors and fly everywhere, which makes the environment seriously polluted. However, through chemical analysis and XRD analysis, the main chemical composition of the surface is cement slurry powder, and the main mineral phase is silica, as well as active components alumina and calcium oxide, so it is a kind of material with potential activity. At present, most of the

\footnotetext{
* Corresponding author: fengym19720315@163.com
} 
utilization of waste concrete in China is concentrated on recycled aggregate, but the research and utilization of recycled fine powder produced in the process of crushing and shaping is still very few, so it is of great significance to study how to make good use of recycled fine powder. Many experts and scholars have made great achievements in the research of recycled powder. Some studies have shown that the activity index of recycled micro powder is about $60 \%-70 \%$, which is similar to that of fly ash [4]. Boudali [5] et al. found that the heat treatment temperature was proportional to the activity of the regenerated powder, and the activity reached the peak at $600{ }^{\circ} \mathrm{C}$. Markin 's research shows that in addition to physical means to stimulate the activity of recycled powder, chemical activator can also be added to the recycled powder to stimulate the activity, so as to effectively improve its activity index [6]. However, there are differences in how to stimulate each chemical activator, the effect after stimulation and the optimal dosage. Many scholars have studied the compressive strength of recycled micro powder concrete, in which the content of micro powder is generally concentrated in 5\% $\sim 30 \%$, and the maximum is $40 \%$ [7]. When the content of micro powder is less than $10 \%$, the compressive strength of concrete is slightly higher than that of concrete without micro powder. When the content is less than $20 \%$, the strength does not decrease obviously; However, when the content exceeds $30 \%$, the strength decreases by about $20.2 \%$. Jiang [8] used plate test to test the early crack resistance of recycled micro powder concrete products. The test conclusion is that when recycled micro powder is added to the concrete sample, the initial cracking time is effectively delayed, and the maximum crack width and length are also significantly shortened, which proves that recycled micro powder can significantly reduce the probability of early cracking of concrete.

The research team will use the red brick powder in the recycled micro powder as the main admixture to replace some cement to prepare the foam concrete, and then study its performance. The maximum use of red brick powder can also meet the relevant specifications of the foam concrete. Mainly from the following aspects. First, different proportion of recycled fine powder is used instead of cement to prepare foam concrete. Then the $28 \mathrm{~d}$ compressive strength, mass water absorption and dry apparent density are measured, and the best amount of recycled fine powder can be determined at the same time when the recycled micro powder is used as much as possible. The regenerated micro powder foamed concrete prepared by different amount of foam stabilizer and the amount of foaming agent was studied. The changing trend of the related properties was tested and compared, and the best mixing amount was found respectively to determine the best mixture ratio. The influence of the amount of recycled fine powder on the thermal conductivity and water absorption of foam concrete is studied.

In view of the limited application of recycled fine aggregate, based on the activity and filling property of recycled fine aggregate and micro powder, the low thermal conductive foamed concrete was prepared by regenerating micropowder instead of some cement. The effects of regenerated fine powder, water binder ratio and
H202 content on the mechanical properties, thermal conductivity and water absorption of the foam concrete were studied. The results showed that as the proportion of recycled fine powder increased, the water absorption of foam concrete increased, dry apparent density, 28d compressive strength and thermal conductivity decreased significantly. The specific research route is shown in Figure 1.

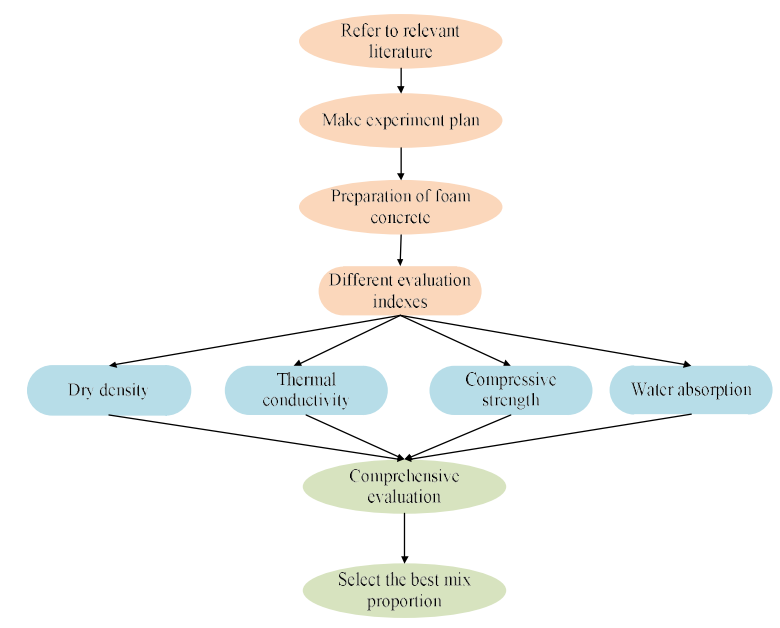

Figure 1 Technology roadmap of recycled fine powder foam concrete

\section{Preparation of recycled fine powder foam concrete}

\subsection{Production of test object}

In this study, we use mortar mixer to prepare recycled fine powder foam concrete. First, we use wet cloth to wet the mixing pot and stirring leaves, and then weigh the cement, red brick powder, foam stabilizer and fiber accurately through accurate electronic scales. Manually stir for 1-2 minutes, then slowly stir for 1-2 minutes with the machine, then add the water in the constant temperature water bath for 1-2 minutes at low speed, finally add the foaming agent, stir for 10 seconds at high speed, quickly pour into the test mold, maintain the test object according to the relevant specifications, demould it after 24 hours, and then put it into the standard curing room for performance test after curing for corresponding time. Figure 2 is a flow chart for the preparation of recycled fine powder foam concrete.

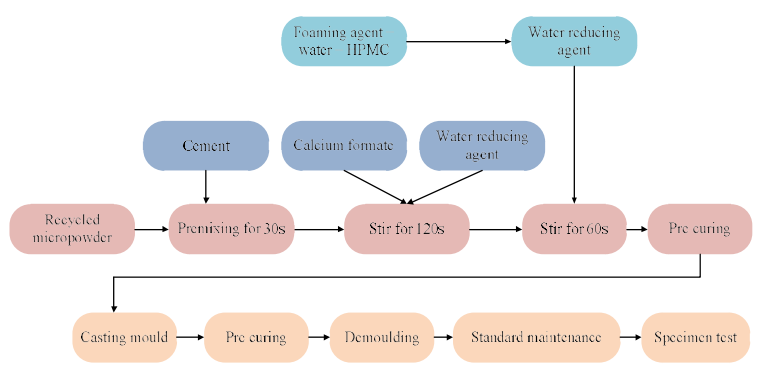

Figure 2 Flow chart of specimen production 


\subsection{Mix proportion of recycled fine powder foam concrete}

The ratio of water to material has a great influence on the preparation and performance of recycled micro powder foamed concrete. When the water is relatively small, the cement paste is over dried, and the amount of water required for red brick powder is greater than that of cement, making it easy to form agglomerate when the slurry is stirred, which leads to the fact that the mixture cannot be evenly mixed. Secondly, when the ratio of water to material is too small, the slurry is too thick. When the foaming agent is added for quick stirring, it cannot be evenly dispersed to all parts of the slurry, and even the foaming agent cannot enter into the slurry, resulting in the failure of the test. When the ratio of water to material is small, the resistance of gas produced by foaming agent to slurry is too large, which makes foaming difficult. The height is too low to reach the predetermined density level, and the distribution and size of pores are different. When the ratio of water to material is too large and the slurry is too thin, the gas produced by foaming agent will escape due to the small resistance, resulting in foaming phenomenon. At the same time, with the increase of the ratio of water to material, the decrease of the strength and dry density of recycled micro powder foam concrete will also accelerate. This is mainly because the main source of strength of recycled micro powder foamed concrete is cement, and the volume of cement will decrease as the ratio of water to material increases, and the strength will not reach the expected goal.

\section{Study on properties of foam concrete}

\subsection{Influence of red brick powder content on properties of foam concrete}

Dry apparent density is one of the most important indexes to evaluate the performance of foamed concrete. Therefore, fly ash is almost the first choice when selecting cementitious materials to replace foam concrete. The main reason is that there is a certain amount of glass in the fly ash after grinding, and the glass is composed of a large number of amorphous silica and aluminum oxide, which has the ability of depolymerization, which can not only improve the working performance of concrete products, but also improve their compressive strength. Therefore, the performance of fly ash is directly proportional to its internal vitreous content. The higher the vitreous content of fly ash, the better its performance. However, fly ash cannot be used as cementitious material alone, because fly ash itself cannot have the same cementitious effect as cement, without the addition of other admixtures. After adding fly ash into cement, it begins to hydration and forms a large amount of $\mathrm{Ca}(\mathrm{OH})_{2}$. The active substances such as $\mathrm{Al}_{2} \mathrm{O}_{3}$ and $\mathrm{SiO}_{2}$ in fly ash can continue to react with it to form secondary hydration. The final hydration products, calcium aluminate hydrate and calcium silicate hydrate, can improve the strength of concrete products. Recycled fine powder is mainly obtained from waste concrete or waste brick and tile after crushing and grinding, which contains a large amount of unhydrated cement slurry powder, a small amount of fine particles of cement stone and limestone, and some $\mathrm{C} 2 \mathrm{~S}, \mathrm{C} 3 \mathrm{~S}$ and $\mathrm{SiO} 2$, so there is a certain possibility of activity. The main material used in this study is recycled red brick powder, whose main chemical composition is basically the same as fly ash and cement, but its raw material is mainly clay, so the content of $\mathrm{SiO} 2$ is relatively high. The related research also shows that the activity index of the milled regenerated powder is more than $65 \%$.

Now the cementitious material system of recycled micro powder foamed concrete has basically been mixed with fly ash and regenerated fine powder. In this experiment, single red brick powder is used instead of cement to prepare recycled foam concrete. At the same time, single fly ash is selected as the control group, which can maximize the utilization of construction waste to regenerate fine powder. To achieve the purpose of reducing costs and resource utilization. In order to make full use of recycled micro powder as much as possible, it is also necessary to ensure that the performance of recycled fine powder foam concrete meets the relevant specifications. In this experiment, the cement content was fixed $60 \%$ to $100 \%$, and the red brick powder was replaced by $0 \%$ to $40 \%$. The performance of the foam concrete under different red brick powder content was tested, and the optimal dosage was selected by comparing the performance. The amount of foaming agent is $4 \%$, the amount of foam stabilizer is $1.2 \%$, the amount of fiber is $0.1 \%$, the water material ratio is 0.6 , and the test water temperature is $30 \pm 1{ }^{\circ} \mathrm{C}$. The amount of other materials is the ratio of cementitious materials. The test mix proportion is shown in table 1 .

Table 1. Test mix proportion of recycled powder

\begin{tabular}{|c|c|c|c|c|}
\hline $\begin{array}{c}\text { Experiment } \\
\text { number }\end{array}$ & Cement\% & $\begin{array}{c}\text { micro } \\
\text { powder\% }\end{array}$ & $\begin{array}{c}\text { Water } \\
\text { material } \\
\text { ratio }\end{array}$ & $\begin{array}{c}\text { foaming } \\
\text { agent\% }\end{array}$ \\
\hline P1 & 100 & 0 & 0.5 & 7 \\
\hline P2 & 90 & 10 & 0.5 & 7 \\
\hline P3 & 80 & 20 & 0.5 & 7 \\
\hline P4 & 70 & 30 & 0.5 & 7 \\
\hline P5 & 60 & 40 & 0.5 & 7 \\
\hline P6 & 50 & 50 & 0.5 & 7 \\
\hline P7 & 40 & 60 & 0.5 & 7 \\
\hline
\end{tabular}

From Figure 3, we can see that the water absorption rate of recycled micro powder foam concrete increases with the increase of red brick powder content, but its water absorption rate increases gradually. When the red brick powder is not added, the water absorption of pure cement foam concrete is $14.3 \%$, which is the lowest among the 7 groups. When the content of red brick powder reaches $60 \%$, the water absorption increases by $4 \%$. It can be concluded that the increase of red brick powder has little effect on the water absorption of recycled fine powder foam concrete. From Figure 3, we can also know that the dry bulk density of the foam concrete in the pure cement group is the largest, and the $28 \mathrm{~d}$ compressive strength is also significantly higher than that of other groups. From this we can know that mixing the red brick powder in the 
foam concrete will reduce the $28 \mathrm{~d}$ compressive strength and dry apparent density, and the main source of strength of the foam concrete is the hydration product produced by the hydration reaction of cement. Therefore, with the increase of red brick powder, the amount of cement will be reduced, the water cement ratio is different, the volume of cement per unit volume will be reduced, and the activity of red brick powder is lower than that of cement. Therefore, the proportion of red brick powder replacing cement will increase, and the compressive strength of recycled concrete foam concrete will decrease accordingly.

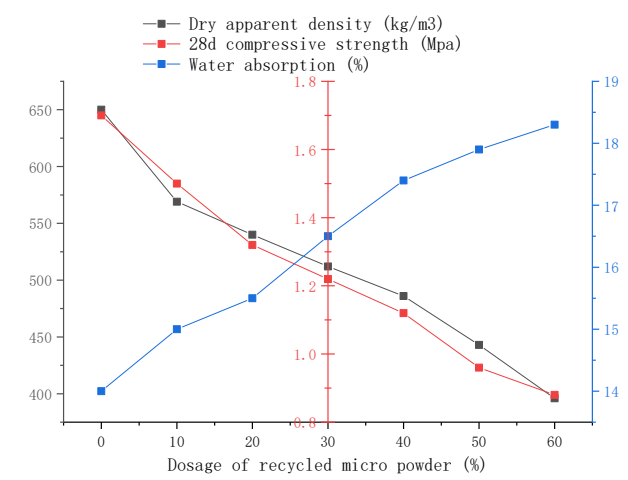

Figure 3 Effect of micro powder on the properties of foam concrete

The recycled micro powder foam concrete contains a large number of closed and disconnected stomata, which has excellent waterproof performance. However, the cementitious materials used in the preparation of foam concrete, such as cement, fly ash, red brick powder and so on, are fine particles. Foam concrete is mainly used as insulation material in the north. The water absorption rate leads to the decrease of freeze-thaw resistance, which limits the application and popularization of recycled fine powder foam concrete. In this experiment, the water absorption rate of recycled fine powder foam concrete increases with the increase of red brick powder content, and also because the red brick itself after crushing and grinding, the quality of the fine powder becomes lighter, the internal gap is large, and the water absorption of the material itself is large. However, the difference of water absorption between the seven groups is less than $5 \%$, and the change of water absorption is related to the compressive strength, dry apparent density and the amount of admixture.

\subsection{Research on thermal conductivity of foam concrete}

Thermal conductivity is one of the most important thermal and moisture properties of building materials, which is closely related to building energy consumption, indoor environment and many other thermal and moisture processes. The thermal conductivity refers to the heat transferred through an area of 1 square meter in 1 second when the temperature difference between the two sides of a $1 \mathrm{~m}$ thick material is 1 degree under the condition of stable heat transfer. Foamed concrete has good thermal performance due to its large number of enclosed small spaces. It can be widely applied to interior and exterior insulation materials of houses. In this section, the thermal conductivity of foam concrete is explored in terms of the amount of recycled fine powder, water binder ratio and hydrogen peroxide.

Figure 4 shows the influence of the replacement rate of recycled micro powder on the thermal conductivity of foam concrete with different proportions of $\mathrm{H} 2 \mathrm{O} 2$. By Figure $4 \mathrm{~A}$, the thermal conductivity of foam concrete decreases with the increase of the amount of recycled fine powder. The reason is that the coarse sugar on the surface of recycled fine powder has a large porosity. When the amount of recycled fine powder increases, the thermal conductivity of foam concrete decreases. From the Figure $4 \mathrm{~B}$, it is found that the thermal conductivity of foam concrete increases first and then decreases with the increase of the amount of recycled fine powder. The reason for this phenomenon is that the coarse particle size of recycled fine powder changes the pore structure of foam concrete and leads to the decrease of thermal conductivity. From Figure 4C, it can be found that when the water gel is relatively low, the replacement rate of recycled fine powder increases, and the thermal conductivity of foam concrete decreases. When the water gel is relatively high, the amount of recycled fine powder has little effect on the thermal conductivity of foam concrete. Compared with the three diagrams, it is found that the influence of the amount of recycled fine powder on the thermal conductivity of foam concrete decreases when the hydrogen peroxide content is increased from 3\% to $9 \%$.

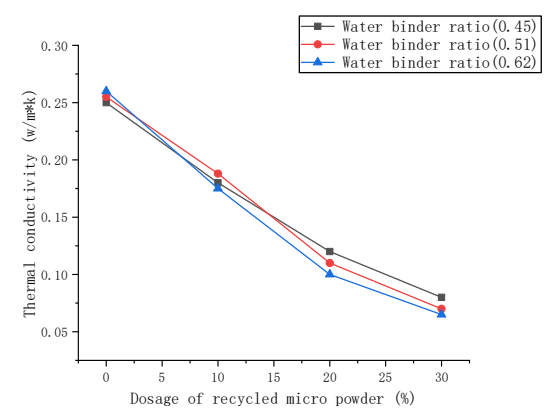

A. $\mathrm{H}_{2} \mathrm{O}_{2}$ dosage $3 \%$

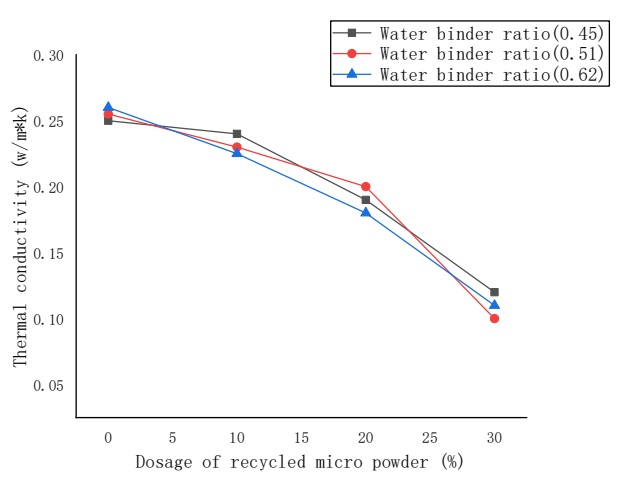

B. $\mathrm{H}_{2} \mathrm{O}_{2}$ dosage $6 \%$ 


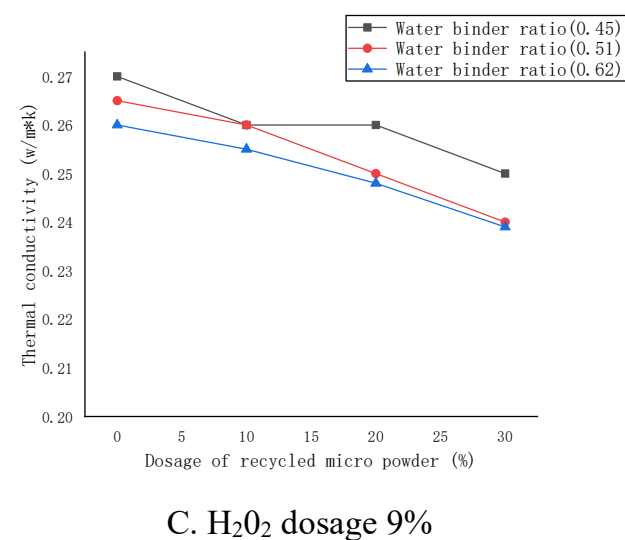

Figure 4 Effect of recycled powder content on thermal conductivity of foamed concrete

\section{Conclusion}

In this paper, the preparation technology, performance and application of recycled micro powder foamed concrete are studied. The feasibility of preparing foam concrete with red brick powder in recycled fine powder is studied, and the best cementing material composition is found by changing the amount of red brick powder instead of cement. The proportion of red brick powder instead of cement is increasing. The dry density of recycled fine powder foam concrete will gradually decrease, and the compressive strength will also decrease, and its water absorption rate will increase slightly. Under the principle of making use of foam concrete as much as possible, cementitious material system (cement: red brick powder $=60: 40$ ) is selected as the best amount of red brick powder. The prepared dry powder foam has a dry apparent density of $502 \mathrm{~kg} / \mathrm{m} 3$, a compressive strength of $1.43 \mathrm{Mpa}$, and a water absorption of $17.1 \%$.

When the content of hydrogen peroxide is $3 \%$ and $6 \%$, the replacement rate of recycled fine powder increases with the addition of regenerated micropowder, and the thermal conductivity of foam concrete is lower. When the amount of hydrogen peroxide is $9 \%$, the replacement rate of recycled fine powder has little effect on the thermal conductivity of foam concrete. When the water binder ratio is 0.62 , the thermal conductivity of foamed concrete with recycled micro fly ash is the lowest. When the content of hydrogen peroxide is $6 \%$, the ratio of water to binder has a greater influence on the thermal conductivity of foam concrete. When the amount of hydrogen peroxide is higher, the influence of water binder ratio on thermal conductivity decreases.

\section{References}

1. Canazza, M A, et al. "New Applications of Tire Powder Recycled by Micro-Waves."Materials Science Forum, vol. 1012, pp. 84-88, 2020.

2. Taherkhani, $\mathrm{H}$, et al. "Investigating the properties of asphalt concrete containing recycled brick powder as filler. " European Journal of Environmental and Civil Engineering, vol. 1, pp. 1-11, 2020.

3. Kasuga, H, et al. "Influence of Addition of Emulsion Polymerized PTFE Powder on Particle Morphology and Mechanical Strength of Recycled PTFE Compacts. " Journal of the Society of Materials Science, vol. 68, pp. 62-67, 2019.

4. Yu, Jiangtao, et al. "Deformability enhancement of fiber-reinforced cementitious composite by incorporating recycled powder. " Journal of Reinforced Plastics and Composites, vol. 39, pp. 119131, 2019.

5. Boudali, S, et al. "Influence of Fine Recycled Concrete Powder on the Compressive Strength of Self-Compacting Concrete (SCC) Using Artificial Neural Network." Sustainability, vol. 13, pp. 3111, 2021.

6. Markin, Nerella, et al. "Material Design and Performance Evaluation of Foam Concrete for Digital Fabrication. " Materials, vol. 12, pp. 2433, 2019.

7. Wei, SW, et al. "Mechanical properties of lightweight foam concrete filler for roadbed of high-speed railway. " Arabian Journal of Geosciences, vol. 14, pp. 1-10, 2021.

8. Jiang, C, et al. "Recycling of waste ceramic foams as fine aggregates in pervious concrete. " RSC Advances, vol. 10, pp. 2364-2367, 2020. 